\title{
Advances of wogonin, an extract from Scutellaria baicalensis, for the treatment of multiple tumors
}

This article was published in the following Dove Press journal:

OncoTargets and Therapy

17 May 2016

Number of times this article has been viewed

\author{
Xue $\mathrm{Wu}^{\prime}$ \\ Haijun Zhang ${ }^{2}$ \\ Jumah Masoud Mohammad \\ Salmani' \\ Rong $\mathrm{Fu}^{3}$ \\ Baoan Chen' \\ 'Department of Hematology, \\ 2Department of Oncology, The \\ Affiliated Zhongda Hospital, School \\ of Medicine, Southeast University, \\ ${ }^{3}$ Department of Physiology, China \\ Pharmaceutical University, Nanjing, \\ People's Republic of China
}

\begin{abstract}
As the major bioactive compound of Scutellaria baicalensis that has been approved to be effective as an anti-inflammatory and antiviral inhibitor in cardiovascular diseases, wogonin (WG) showed potent and promising antitumor effects both in vitro and in vivo. It has been proved that WG has the ability to inhibit the growth of tumor cells, induce apoptosis, and suppress angiogenesis. The molecular mechanisms involve reactive oxygen species, $\mathrm{Ca}^{2+}$, $\mathrm{NF}-\kappa \mathrm{B}$, tumor necrosis factor-related apoptosis-inducing ligand, and tumor necrosis factor-alpha. Furthermore, the synergistic effect of WG with 5-fluorouracil, etoposide, and adriamycin to enhance chemotherapy and reverse drug resistance has also been confirmed. In this review, we summarize the advances in recent years on the antitumor effect of WG on multiple tumors; in addition, we also present information regarding the synergistic and chemosensitizing effects of WG with other drugs to illustrate its potential use in the clinic.
\end{abstract}

Keywords: antitumor effect, drug resistance, mechanisms, synergistic effect

\section{Introduction}

During the last 20 years, wogonin (WG; 5,7-dihydroxy-8-methoxyflavone) was identified as a potent apoptosis inducer of cancer cells, showing its maximal efficacy with minor side effects. ${ }^{1}$ Furthermore, pharmacokinetic studies in rats make the use of WG in the clinic possible. ${ }^{2}$ Fortunately, it has been approved for Phase I clinical trial in the People's Republic of China (December 2014, approved by the China Food and Drug Administration).

WG is extracted from Scutellaria baicalensis Georgi (Huang Qin), a perennial Labiate, and its molecular formula is $\mathrm{C}_{16} \mathrm{H}_{12} \mathrm{O}_{5}$ (Figure 1). Several studies have shown its inhibitory activity on the viability and the growth of tumor cells. ${ }^{3}$ Various investigations have also demonstrated that WG exerts its antitumor effects via regulation of multiple molecular pathways. The key molecular pathways of its antitumor effects include reactive oxygen species (ROS), $\mathrm{Ca}^{2+}, \mathrm{NF}-\kappa \mathrm{B}$, tumor necrosis factor-related apoptosis-inducing ligand (TRAIL), and tumor necrosis factor-alpha, ${ }^{4-8}$ which participate in both intrinsic mitochondria-mediated and extrinsic receptor-mediated pathways. ${ }^{9}$ In addition to its activation of Bax/Bak protein and caspase-8/caspase-9/caspase-3, WG plays an important role to inhibit lipopolysaccharide-induced or hydrogen peroxide $\left(\mathrm{H}_{2} \mathrm{O}_{2}\right)$-induced tumor angiogenesis through PI3K/AKT/NF- $\mathrm{BB}$ pathway. ${ }^{10-12}$ In addition, the ability of WG to inhibit tumor angiogenesis by decreasing the expression of hypoxia-inducible factor-1 $\alpha$ protein was also observed. ${ }^{13}$

The current review is not only limited to the induction of apoptosis of tumor cells by WG but also dedicated to its synergistic effects with other chemotherapeutic
Correspondence: Baoan Chen Department of Hematology, The Affiliated Zhongda Hospital, School of Medicine, Southeast University, Dingjiaqiao 87, Nanjing 210009 , Jiangsu Province, People's Republic of China Tel +86 I385I 665838 Email cba8888@hotmail.com 


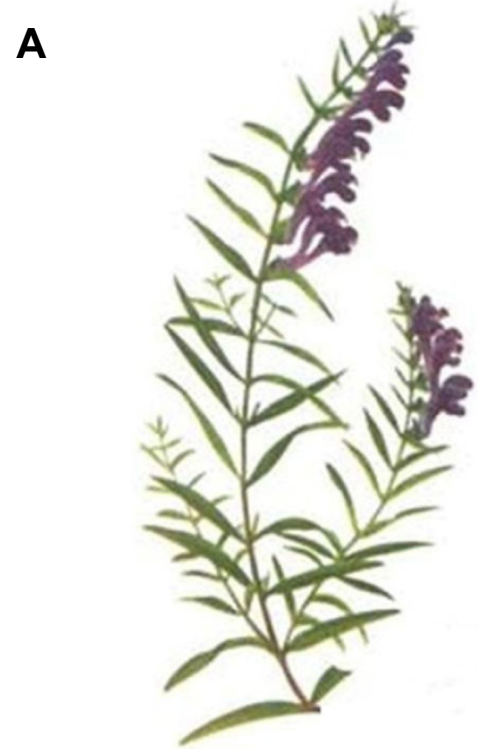

Figure I Scutellaria baicalensis Georgi (Huang Qin) and WG.

Notes: (A) The plant of Huang Qin. (B) The chemical structure of WG. Abbreviation: WG, wogonin.

drugs and its ability to reverse drug resistance of tumors (chemosensitizer), aiming to summarize its new developments for its future clinical use.

\section{Anticancer effects on multiple tumors in vitro and in vivo Hematologic malignancies}

Leukemia, multiple myeloma, and lymphoma are the three main kinds of hematologic malignancies with the highest mortality rate. Since the study of Huang et $\mathrm{al}^{14}$ in 2010 where they investigated the effects of 29 compounds from the extracts of $S$. baicalensis on leukemia cell lines, WG's ability to induce apoptosis in tumor cells has been considered. At the same time, the extracts from Scutellaria pinnatifida, such as dichloromethane, methyl alcohol, ethyl acetate, and $n$-butyl alcohol, were tested on two different leukemia cell lines and a normal cell line, by Boozari et al. ${ }^{15}$ Among them, the extract of dichloromethane showed the highest cytotoxic effects and the possibility to regulate the expression of the proteins, which were related to apoptosis, and the cell cycle was blocked at the G1 phase. Furthermore, the study also showed that WG was the main active component in the dichloromethane extract of $S$. pinnatifida, indicating its role as a cytotoxic drug. ${ }^{15}$ On the other hand, Ozmen et al ${ }^{16}$ demonstrated that WG could induce genotoxic stress at the concentration of $132 \mu \mathrm{g} / \mathrm{mL}$ on HL-60 cells after treatment for 48 hours, leading to the appearance of substantial phosphorylation of the core histone $\mathrm{H} 2 \mathrm{AX}$ (gamma-H2AX)
B<smiles>COc1c(O)cc(O)c2c1OC(c1ccccc1)CC2=O</smiles>

5,7-dihydroxy-8-methoxyflavone followed by the activation of caspase- 3 and signature-type cleavage of PARP, which caused apoptosis in $>55 \%$ of HL-60 cells.

Moreover, the anticancer effect of WG was investigated in the mouse model of leukemia. A study in vivo showed that WG could increase the survival rate of leukemic mice by increasing the percentage of CD3 (T cells) and CD19 (B cells) and reducing the percentage of Mac-3 (macrophages) and CD11b (monocytes) cell surface markers. ${ }^{17}$ In 2014, peripheral blood leukocytes obtained from patients with acute lymphoblastic leukemia were used to identify the antitumor potential of WG. Interestingly, the results confirmed that WG is not only capable of inducing the apoptosis of acute lymphoblastic leukemia cells but also has good selectivity for tumor cells. ${ }^{18}$

Research on the possible effects of WG for the treatment of multiple myeloma and lymphoma have been explored as well. The studies both in vitro and in vivo confirmed that $\mathrm{WG}$ induced apoptosis of myeloma cells via the intrinsic apoptotic pathway, ${ }^{19,20}$ which made WG a potential therapeutic drug for multiple myeloma. On the other hand, Wang et al investigated the effect of WG on lymphoma cells, and the result showed that WG could induce the apoptosis of B-cell lymphoma. Furthermore, they combined WG with magnetic nanoparticles as a drug delivery system to explore whether it could increase the efficiency of WG-induced apoptosis, which opened another era for the use of Chinese traditional medicines with advanced technologies for drug delivery. ${ }^{21}$ 


\section{Solid tumors}

Solid tumors account for $\sim 90 \%$ of all cancers. The recorded death rate in the US was $23 \%$ of the total population in 2011. Previously, due to the limited use of effective therapies, solid tumors represent a major cause of death. A decrease in the mortality rate caused by cancers from 2011 to 2015 was recorded, as the molecular mechanisms for tumor development were explored widely; in addition, new drugs were designed and introduced as targeted chemotherapeutic agents. ${ }^{22}$ The underlying molecular mechanisms by which WG has been demonstrated to exert its effect as antitumor agent are summarized in Table 1.

\section{Digestive carcinomas}

Hepatocellular carcinoma (HCC) is a refractory malignancy, which has a high incidence and mortality rate all over the world, especially among Asian populations. ${ }^{23}$ Lack of systemic chemotherapeutic regimens and effective surgical resection results in poor prognosis in most patients. In recent years, natural products have been increasingly recognized as new remedies for enhancing the efficacy and alleviating the adverse effects of tumor therapies. To explore the antitumor effects of WG on HCC, Xu et al evaluated the efficacy of WG on three types of HCC cell lines and tumor cell xenografts as well. The results confirmed the induced-apoptotic effect of WG on HCC and indicated that the resultant cytotoxicity was partially attributed to the unfolded protein response where AKT pathways played an important role in that process. The production of intracellular $\mathrm{H}_{2} \mathrm{O}_{2}$ and the release of endoplasmic reticulum (ER) $\mathrm{Ca}^{2+}$ might be the beginning of this effect. ${ }^{24}$

Most colorectal cancers (CRC) have high incidence in people from the developed countries rather than those from the developing countries. The incidence and mortality rates

Table I Molecular mechanisms through which WG interacts with various types of tumors

\begin{tabular}{|c|c|c|c|}
\hline Tumor type & Cell lines & Key signaling & References \\
\hline \multirow[t]{3}{*}{ Leukemia } & HL-60 & Caspase-3 $3 \uparrow, \mathrm{Bcl}-2 \downarrow$, telomerase activity $\downarrow$ & 14 \\
\hline & & $\begin{array}{l}\text { Caspase- } 3 \uparrow, \mathrm{H} 2 \mathrm{AX} \text { phosphorylation, cleavage } \\
\text { of PARP }\end{array}$ & 15,16 \\
\hline & NALM-6 & VEGF, сMyс, NF-кB $\downarrow$ & 18 \\
\hline Multiple myeloma & 8226 & ABCG2 protein $\downarrow$, Aktl protein $\downarrow$ & 19,20 \\
\hline \multirow[t]{4}{*}{$\mathrm{HCC}$} & HepG2 & Bcl-2 $\downarrow$, Bax protein $\uparrow$, pro-caspase- $3 \uparrow$ & 24 \\
\hline & & ROS, ER stress & 24 \\
\hline & & Nrf2 $\downarrow$ & 24 \\
\hline & SMMC-772I & 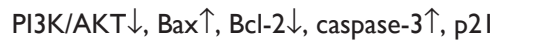 & 24 \\
\hline \multirow[t]{3}{*}{ CRC } & HCTII6 & HIF-I $\alpha \downarrow$, PI3K/AKT $\downarrow$ & 29 \\
\hline & & GI arrest, $W n t / \beta$-catenin $\downarrow$ & 30 \\
\hline & HT-29 & NF-кB, Nrf2, AKT & $27,31,32$ \\
\hline \multirow[t]{3}{*}{ Breast cancer } & MCF-7 & $\mathrm{PI} 3 \mathrm{~K} / \mathrm{AKT} \downarrow$ & $11,36-38$ \\
\hline & & ERK $\uparrow, p 38$ MAPKs $\uparrow$, HIF-I $\alpha \uparrow$ & 39 \\
\hline & MDA-MB-23I & PKC $\delta \downarrow$, ERK phosphorylation, MMP-9 $\downarrow$ & 40 \\
\hline \multirow[t]{5}{*}{ Glioma } & F98 & 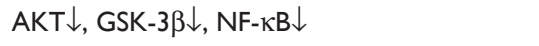 & 47 \\
\hline & C6 and U25I &  & 48 \\
\hline & GBM840I & PKC $\alpha$, ERK, NF-кB, MMP-9 & 49 \\
\hline & U87 and U25I & ROS, ER stress & $50,5 I, 53$ \\
\hline & U87-MG, U343-MG, U373, T98G, and MCF-I0A & AMPK, p53 & 52 \\
\hline \multirow[t]{5}{*}{ Lung cancer } & A549 & $\mathrm{p} 53 \uparrow, \mathrm{Bax} \uparrow$ & 55 \\
\hline & & ROS & 56 \\
\hline & & IL-6/STAT3 & 57 \\
\hline & & COX-2 $\downarrow$, c-Jun $\downarrow, A P-I \downarrow$ & 58 \\
\hline & SK-MES-I &  & 55 \\
\hline \multirow[t]{2}{*}{ Cervical cancer } & HeLa & p53, p2ICipl & 59 \\
\hline & HPV-I6 & $E 6 \downarrow, E 7 \downarrow$ & 60 \\
\hline \multirow[t]{2}{*}{ Nasopharyngeal carcinoma } & NPC-TW076/039 & 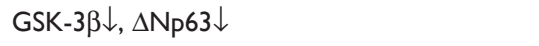 & 61 \\
\hline & & mTOR/P70S6K, AKT, Raf/ERK & 62 \\
\hline Osteosarcoma & U-2 OS & ER stress & 63 \\
\hline Melanoma & B60-FIO & $\begin{array}{l}\text { Extracellular regulated protein kinases and } \\
\text { protein kinase } B\end{array}$ & 64 \\
\hline
\end{tabular}

Abbreviations: HCC, hepatocellular carcinoma; CRC, colorectal cancer; WG, wogonin; ROS, reactive oxygen species; ER, endoplasmic reticulum; Nrf2, NF-E2-related factor 2; ERK, extracellular signal-regulated kinase. 
for the elderly population in the more developed areas were $4.3 \%$ and $1.6 \%$, respectively. ${ }^{23}$ The exploration of WG effects on CRC was always accompanied by the discoveries of colitis and inflammation-associated colorectal carcinogenesis, ${ }^{25,26}$ in which the key molecules involved were discovered recently to be NF- $\kappa$ B and NF-E2-related factor 2 (Nrf2). ${ }^{27}$ A study in 2013 showed that WG had a strong chemosensitizing effect in HCT116 cells under hypoxia. The suggested molecular mechanism might be that WG could downregulate the expression of HIF-1 $\alpha$, which activated the expression of related target genes through inhibiting PI3K/AKT signaling pathway in vitro and in vivo. ${ }^{28}$ Meanwhile, He et al also demonstrated that WG could induce cell cycle arrest at the G1 phase in HCT116 cells in a concentration and time-dependent manner by downregulating $\mathrm{Wnt} / \beta$-catenin signaling pathway. ${ }^{29}$ The current reports about the mechanisms of WG-induced apoptosis in HT-29 colon cancer cells include mitochondrialmediated pathway, AKT inactivation, and p53-dependent manner. ${ }^{30,31}$ Besides HCC and CRC, evidence on the potential of WG to induce the apoptosis in gallbladder carcinoma and pancreatic cancer still need further exploration. ${ }^{32-34}$

\section{Breast cancer}

Because of its poor prognosis, breast cancer caused $15 \%$ of tumor-related death in females, ranking as the second major malignancy in the US in 2015. ${ }^{22}$ Although new chemotherapeutic drugs and target therapeutic preparations have been introduced, the rate of death continues to rise. A study in 2010 showed that baicalin-deprived-fraction, but not the whole extract of $S$. baicalensis, might have potential to inhibit cell growth and induce cell apoptosis of MCF-7 cells through the PI3K/AKT pathway, which played a critical role as an important signaling downstream of epidermal growth factor receptor for breast cancer. ${ }^{35}$ Since then, much research has focused on the relationship between the PI3K/AKT pathway and MCF-7 breast cancer cell line. However, the limitation was that almost all the results were restricted to the in vitro experiments, whereas studies in vivo and clinical trials were not reported. ${ }^{36,37}$ Besides being a promising inhibitor of tumor angiogenesis, WG was evaluated by Zhao et $\mathrm{al}^{11}$ to investigate its antitumor effect on breast cancer cells. They concluded that WG could inhibit AKT signaling, suppress tumor angiogenesis, and depress tumor growth eventually.

Recent studies also indicated that the activation of extracellular signal-regulated kinase and p38 MAPKs signaling pathways, which could be inhibited by $N$-acetyl cysteine, an ROS scavenger, was correlated with the cell apoptosis in breast cancer cells treated with WG. ${ }^{38}$
Therefore, it could be concluded that WG effects on breast cancer might be through ROS pathway. ${ }^{39}$ In addition to the apoptosis of cancer cells, extracellular signal-regulated kinase also participates in the invasion of breast cancer, which could be inhibited by WG, indicating that WG is an inhibitor of tumor invasion as well. ${ }^{40}$

\section{Neuroblastoma and glioma}

As a new potential drug for diseases of the nervous system, WG takes effect as an anti-inflammatory, neuroprotective, and tumor growth inhibitor. ${ }^{41-44}$ The former two effects were confirmed to be associated with NF- $\kappa \mathrm{B}$ and MAPK signaling pathway both in primary microglial cell cultures and in rat dorsal root ganglion neurons. ${ }^{45,46}$ Actually, they also interact with each other since NF- $\kappa \mathrm{B}$ and MAPK signaling also played a critical role in tumor inhibition or apoptosis. In 2011, Parajuli et $\mathrm{al}^{47}$ were the first to provide an in vivo evidence about the antiglioma activity of WG, demonstrating that the suppressed growth of the tumor was due to the inhibition of AKT and its downstream signaling, including glycogen synthase kinase (GSK-3) and NF- $\kappa$ B. The inhibition of GSK-3 $\beta$ has also been recognized as a key change to induce the differentiation of glioma cells treated with WG. Moreover, in 2013, Wang et $\mathrm{al}^{48}$ found that WG could induce the differentiation of glioma cells by diminishing the phosphorylation of AKT and decreasing the expression of $\beta$-catenin significantly, both of which were dependent on GSK-3 $\beta$ activation. Meanwhile, Lin et $\mathrm{a}^{49}$ used WG in one study, known as NF- $\mathrm{KB}$ inhibitor, to prevent the migration and invasion of glioblastoma, indicating that the anticancer effect of WG included inhibition of tumor metastasis as well. Other studies of WG on glioma focused on the mechanisms of WG-induced apoptosis that include ROS activation and ER stress activation and mitochondrial dysfunction both in vitro and in vivo. ${ }^{50-53}$

\section{Lung cancer}

Lung cancer accounts for $14 \%$ of the newly estimated cases in 2015 and is the leading cause of mortality among all cancers. $^{22}$ In 2010, Gao et $\mathrm{al}^{54}$ for the first time evaluated the inhibitory effect of eight solvent extracts from S. baicalensis on a human lung cancer cell line confirming the role of WG as an inhibitor of human lung cancer. In order to figure out the mechanism as to how WG affects lung cancer, Gao et $\mathrm{al}^{55}$ continued the exploration on other lung cancer cell lines, which showed that WG also had the ability to induce the apoptosis of tumor cells. Meanwhile, the in vitro studies about the effect of WG on enhancing TRAIL-induced apoptosis in lung cancer cells has been already in progress 
as well, as in 2013 and based on the in vitro xenografts investigation results, showed that WG significantly enhanced TRAIL-induced suppression of tumor growth that was regulated by the ROS signaling pathway. ${ }^{56}$ Additionally, evidence showed that WG had the ability to depress tumor metastasis by regulating the inflammatory microenvironment, ${ }^{57} \mathrm{dem}$ onstrating that it is an effective therapeutic drug for tumor migration. ${ }^{58}$

\section{Others}

There is also some research about the antitumor effect of WG on cervical cancer, ovarian tumor, nasopharyngeal carcinoma, osteosarcoma, and melanoma. However, most of the investigations were limited to an in vitro evaluation, and the data indicated that AKT, GSK-3 $\beta$, and ER stress played an important role in the process of apoptosis induced by WG. ${ }^{59-64}$

\section{Synergistic reactions with other chemotherapeutic drugs}

WG is considered as an adjuvant to potentiate the antitumor efficacy of the drugs and reduce their damage to normal tissues for cancers such as leukemia and HCC. ${ }^{65,66}$ The combination of WG with 5-fluorouracil (5-FU), etoposide, and paclitaxel (PTX) has been widely reported for the treatment of hematological and gastric malignancies (Table 2).

\section{Combination of WG and 5-FU}

The use of 5-FU for gastrointestinal cancers in the clinic as an antitumor agent, has a long history of more than half of a century. 5-FU prevents tumor growth by abnormal RNA processing and inhibition of DNA synthesis. However, the unaided use of 5-FU in advanced gastrointestinal cancers generally leads to a very low rate of response and most frequently drug resistance. Thus, the ability of WG as a potential antitumor and chemosensitizing drug was tested to enhance the antitumor effect of 5-FU and minimize drug resistance.
Two positive results were reported indicating the synergistic effect of WG and 5-FU both in vitro and in vivo. The first one concluded that WG mechanism was due to the inhibition of NF- $\kappa \mathrm{B},{ }^{67}$ while the other study found that WG enhanced the effect of 5-FU cytotoxicity in HCC through the PI3K/ AKT signaling pathway. ${ }^{68}$

\section{Potentiation of the antitumor effect of etoposide and amelioration of its adverse effects}

Etoposide, an antitumor agent for specific cell cycle arrest, is targeted for DNA topoisomerase-II enzyme. It forms a ternary complex with DNA and the topoisomerase II enzyme, preventing the religation of the DNA strands, causing DNA strands to break. Because of its DNA damage effect, normal cells are usually killed during the process of clearing tumor cells, which causes severe myelosuppression. The low toxicity of WG was indicated by the fact that it did not affect the viability of normal $\mathrm{T}$ cells and usually acted as an antiapoptotic agent for thymocytes. ${ }^{69}$ Enomoto et al cultured various tumor cells with normal $\mathrm{T}$ cells from mice thymus and bone marrow treated with etoposide alone, WG alone, or etoposide combined with WG. The results showed that the cells treated by the combination group had a higher apoptotic rate than both untreated cells and single drug (etoposide or WG) treated cells. However, compared with the group which was treated with etoposide alone, the apoptosis rate of normal $\mathrm{T}$ cells of the combination group was much lower. Further study showed that WG inhibited the excretion of calcein, a substrate for P-glycoprotein (P-gp) in the tumor cells, and decreased the excretion of etoposide; thus, it increased the intracellular content of etoposide.$^{69}$ In another study, the attenuating effect of WG on etoposide-induced oxidative DNA damage of normal cells was also investigated in mouse bone marrow cells using oral administration of WG before etoposide injection, which was correlated with the downregulation of OGG1 repair gene and changes in oxidative DNA stress. ${ }^{70}$

Table 2 Common drugs that have synergistic effect with WG and their effects

\begin{tabular}{|c|c|c|c|c|}
\hline Name of drug & Tumor type & Effects & In vitro & In vivo \\
\hline \multirow[t]{3}{*}{$5-\mathrm{FU}$} & Gastrointestinal cancers & Inhibiting the expression of NF- $\mathrm{KB}$ & $\sqrt{ }$ & $\sqrt{ }$ \\
\hline & & Enhancing the cytotoxicity to HCC, which & & \\
\hline & & expressed high COX-2 by PI3K/AKT & & \\
\hline \multirow[t]{2}{*}{ Etoposide } & Leukemia and lung cancer & Decreasing the etoposide-induced oxidative & $\sqrt{ }$ & \\
\hline & & DNA damage and apoptosis of other hemocytes & & \\
\hline \multirow[t]{3}{*}{ PTX } & Gastrointestinal cancers & $\mathrm{IC}_{50}$ of the combination has been calculated & $\sqrt{ }$ & $\sqrt{ }$ \\
\hline & & for four gastric cancer cell lines, but no further & & \\
\hline & & research was conducted on its mechanisms & & \\
\hline
\end{tabular}

Note: $\sqrt{ }$ means that the relevant studies have been done already.

Abbreviations: WG, wogonin; 5-FU, 5-fluorouracil; HCC, hepatocellular carcinoma; PTX, paclitaxel. 


\section{Synergistic effect of WG and PTX}

PTX is widely used in antigastric cancers and breast cancers combined with other chemotherapeutic agents such as cisplatin and adriamycin. However, the combinations often bring about severe side effects. The study of Wang et al demonstrated the low $\mathrm{IC}_{50}$ and high apoptotic rate of WG and PTX on four gastric cancer cell lines. It was therefore concluded that the combination of WG and PTX had a synergistic inhibitory effect on tumor growth in vitro; a further study also affirmed the result in vivo. ${ }^{71}$

\section{Development of WG-Lip complex with other chemotherapeutic drugs}

In addition to mixing free plain WG physically with chemotherapeutic drugs to induce antitumor effects, Tian et al connected free WG with liposomes (Lip) to produce WG-Lip complex and then modified the complex by glycyrrhetinic acid (GA) in order to get the final product, namely, GAmodified WG Lip (GA-WG-Lip). GA-WG-Lip showed a great rate of uptake and had an $\mathrm{IC}_{50}$ value 1.46 times higher than that of WG-Lip. Other advantages of the GA-modified WG Lip included rapidly accumulating in the liver and displaying a better tumor inhibitory effect than that of the unmodified Lip. ${ }^{72}$ Therefore, the future of WG combination with other drugs will not be limited to simple mixing, but the introduction of pharmaceutically modified formulation of WG will predominate the future explorations to achieve better responses and to overcome free WG administration problems.

\section{Chemosensitizing effect}

As a major chemotherapeutic obstacle, multidrug resistance (MDR) is currently rendering many available chemotherapeutic drugs ineffective for treating tumors. Researchers found that the inhibition of MDR proteins by WG could improve the intracellular effective drug level and potentiate their chemotherapeutic effects. ${ }^{73}$ Imatinib is a BCR-ABL kinase inhibitor that is widely used in the clinic for chronic myelogenous leukemia. However, resistance to imatinib leads to a high rate of treatment failure. The study of Yang et al ${ }^{74}$ indicated that WG could inhibit the growth of K562r, one of the MDR cell lines of chronic myelogenous leukemia, and arrest cell cycle at the G0/G1 phase. Besides, the adriamycin-resistant K562 cells (K562/A02) were also used to test the chemosensitizing effect of WG, whose mechanism was discovered to be associated with downregulation of MDR protein 1 expression by inhibiting Nrf2/ARE signaling pathway eventually (Figure 2) ${ }^{75}$ Moreover, WG could also reverse adriamycin resistance of breast cancer cells MCF7/DOX by regulating the expression of P-gp. ${ }^{76}$ Commonly, P-gp has been reported to develop not only the resistance of adriamycin-treated cells but also etoposide-induced apoptosis, which was also a target of WG to chemosensitize in many tumor cells. ${ }^{21,77,78}$

The effect of sensitizing other chemotherapeutic drugs with WG was also explored in lung cancer, ovarian cancer, and colon cancer which are resistant to traditional chemotherapeutic drugs, for example, platinum. Meanwhile, in addition to the chemosensitizing effect, WG could also enhance the antitumor effect of chemotherapeutic drugs under the



Figure $\mathbf{2}$ The chemosensitizing of WG by Nrf2-mediated pathway.

Note: WG downregulates the expression of PI3K/Akt to reduce the transcription of Nrf2 mRNA and results in inhibition of MRPI.

Abbreviations: WG, wogonin; Nrf2, NF-E2-related factor 2; MRPI, multidrug resistance protein I. 


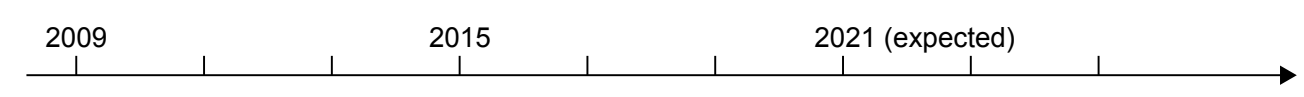

\section{Searching and}

discovering

Estimating

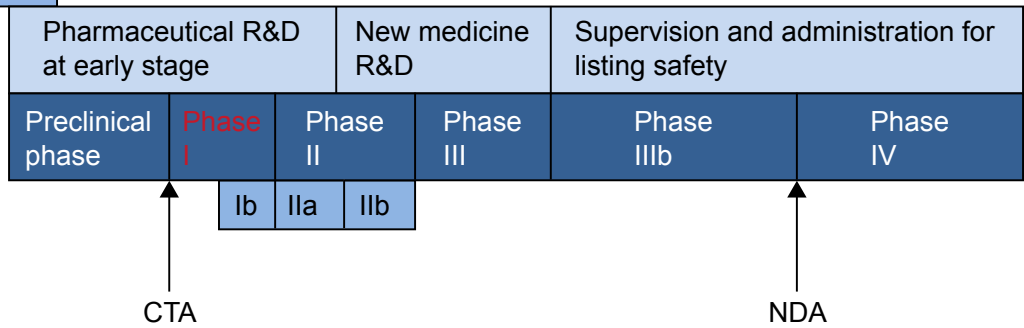

Figure 3 The procedures for WG to be a clinically approved drug.

Note: The red words of Phase I indicate the place where we are currently.

Abbreviations: WG, wogonin; R\&D, research and development; CTA, clinical trial admission; NDA, new drug admission.

condition of hypoxia resistance, expanding the use of $\mathrm{WG}$ as a potential antitumor drug. ${ }^{28,79,80}$

\section{Summary and perspectives}

In the past few years, research on WG has improved dramatically. Currently, almost all types of cancer have been investigated to explore the effect of WG, especially in $\mathrm{HCC}$ and leukemia. Accumulating evidence shows that WG not only targets the key molecules, which play an important role in the development of tumors, but also enhances the anticancer effect of chemotherapeutic drugs. What is more, based on the explorations both in vitro and in vivo, WG has been approved for Phase I trials in the People's Republic of China, which is a milestone for its clinical use in the future. Figure 3 shows the procedures required for WG to be a clinically approved drug.

However, although WG has been identified to suppress the growth of multiple tumors and induce apoptosis, results are still limited in some tumors in in vitro investigations. Thus, it is extremely urgent to complete the pharmacokinetic data for WG. Meanwhile, existing results on synergistic and chemosensitizing effects are mostly based on 5-FU, etoposide, PTX, and adriamycin; therefore, future investigations need to search for other drugs that can interact with WG to enhance anticancer effects.

\section{Acknowledgments}

This work was supported by the Key Department of Jiangsu Medicine (2012-12), National Natural Science Foundation of China (81370673), and Key Medical Projects of Jiangsu Province (BL2014078).

\section{Disclosure}

The authors report no conflicts of interest in this work.

\section{References}

1. Li-Weber M. New therapeutic aspects of flavones: the anticancer properties of Scutellaria and its main active constituents wogonin, baicalein and baicalin. Cancer Treat Rev. 2009;35(1):57-68.

2. Talbi A, Zhao D, Liu Q, et al. Pharmacokinetics, tissue distribution, excretion and plasma protein binding studies of wogonin in rats. Molecules. 2014;19(5):5538-5549.

3. He H, Han S, Zhang T, Zhang J, Wang S, Hou J. Screening active compounds acting on the epidermal growth factor receptor from radix scutellariae via cell membrane chromatography online coupled with HPLC/MS. J Pharm Biomed Anal. 2012;62:196-202.

4. Kallifatidis G, Rausch V, Baumann B, et al. Sulforaphane targets pancreatic tumour-initiating cells by NF-kappaB-induced antiapoptotic signalling. Gut. 2009;58(7):949-963.

5. Yang L, Zheng XL, Sun H, et al. Catalase suppression-mediated $\mathrm{H}(2)$ $\mathrm{O}(2)$ accumulation in cancer cells by wogonin effectively blocks tumor necrosis factor-induced NF-kappaB activation and sensitizes apoptosis. Cancer Sci. 2011;102(4):870-876.

6. Lee DH, Rhee JG, Lee YJ. Reactive oxygen species up-regulate p53 and Puma; a possible mechanism for apoptosis during combined treatment with TRAIL and wogonin. Br J Pharmacol. 2009;157(7):1189-1202.

7. Rushworth SA, Micheau O. Molecular crosstalk between TRAIL and natural antioxidants in the treatment of cancer. Br J Pharmacol. 2009; 157(7):1186-1188.

8. Ding J, Polier G, Kohler R, Giaisi M, Krammer PH, Li-Weber M. Wogonin and related natural flavones overcome tumor necrosis factorrelated apoptosis-inducing ligand (TRAIL) protein resistance of tumors by down-regulation of c-FLIP protein and up-regulation of TRAIL receptor 2 expression. J Biol Chem. 2012;287(1):641-649.

9. Li-Weber M. Targeting apoptosis pathways in cancer by Chinese medicine. Cancer Lett. 2013;332(2):304-312.

10. Lin CM, Chen YH, Ong JR, Ma HP, Shyu KG, Bai KJ. Functional role of wogonin in anti-angiogenesis. Am J Chin Med. 2012;40(2):415-427.

11. Zhao K, Song X, Huang Y, et al. Wogonin inhibits LPS-induced tumor angiogenesis via suppressing PI3K/Akt/NF-kappaB signaling. Eur J Pharmacol. 2014;737:57-69.

12. Zhou M, Song X, Huang Y, et al. Wogonin inhibits $\mathrm{H}_{2} \mathrm{O}_{2}$-induced angiogenesis via suppressing $\mathrm{PI} 3 \mathrm{~K} / \mathrm{Akt} / \mathrm{NF}-\mathrm{kappaB}$ signaling pathway. Vascul Pharmacol. 2014;60(3):110-119.

13. Song X, Yao J, Wang F, et al. Wogonin inhibits tumor angiogenesis via degradation of HIF-1 alpha protein. Toxicol Appl Pharmacol. 2013; 271(2):144-155.

14. Huang ST, Wang CY, Yang RC, Chu CJ, Wu HT, Pang JH. Wogonin, an active compound in Scutellaria baicalensis, induces apoptosis and reduces telomerase activity in the HL-60 leukemia cells. Phytomedicine. 2010;17(1):47-54 
15. Boozari M, Mohammadi A, Asili J, Emami SA, Tayarani-Najaran Z. Growth inhibition and apoptosis induction by Scutellaria pinnatifida A. Ham. on HL-60 and K562 leukemic cell lines. Environ Toxicol Pharmacol. 2015;39(1):307-312.

16. Ozmen A, Madlener S, Bauer S, et al. In vitro anti-leukemic activity of the ethno-pharmacological plant Scutellaria orientalis ssp. carica endemic to western Turkey. Phytomedicine. 2010;17(1):55-62.

17. Lin CC, Lin JJ, Wu PP, et al. Wogonin, a natural and biologically-active flavonoid, influences a murine WEHI-3 leukemia model in vivo through enhancing populations of T- and B-cells. In Vivo. 2013;27(6):733-738.

18. Orzechowska B, Chaber R, Wisniewska A, et al. Baicalin from the extract of Scutellaria baicalensis affects the innate immunity and apoptosis in leukocytes of children with acute lymphocytic leukemia. Int Immunopharmacol. 2014;23(2):558-567.

19. Lin MG, Liu LP, Li CY, et al. Scutellaria extract decreases the proportion of side population cells in a myeloma cell line by down-regulating the expression of ABCG2 protein. Asian Pac J Cancer Prev. 2013; 14(12):7179-7186.

20. Zhang M, Liu LP, Chen Y, et al. Wogonin induces apoptosis in RPMI 8226 , a human myeloma cell line, by downregulating phospho-Akt and overexpressing Bax. Life Sci. 2013;92(1):55-62.

21. Wang L, Zhang H, Chen B, et al. Effect of magnetic nanoparticles on apoptosis and cell cycle induced by wogonin in Raji cells. Int J Nanomedicine. 2012;7:789-798.

22. Siegel RL, Miller KD, Jemal A. Cancer statistics, 2015. CA Cancer J Clin. 2015;65(1):5-29.

23. Torre LA, Bray F, Siegel RL, Ferlay J, Lortet-Tieulent J, Jemal A. Global cancer statistics, 2012. CA Cancer J Clin. 2015;65(2):87-108.

24. Xu M, Lu N, Zhang H, et al. Wogonin induced cytotoxicity in human hepatocellular carcinoma cells by activation of unfolded protein response and inactivation of AKT. Hepatol Res. 2013;43(8):890-905.

25. Han XH, Zhong J, Guo JY, et al. Relationships between pharmacokinetics and efficacy of Xie-xin decoction in rats with experimental ulcerative colitis. J Ethnopharmacol. 2013;148(1):182-189.

26. Jiang WY, Seo GS, Kim YC, Sohn DH, Lee SH. PF2405, standardized fraction of Scutellaria baicalensis, ameliorates colitis in vitro and in vivo. Arch Pharm Res. 2015;38(6):1127-1137.

27. Yao J, Zhao L, Zhao Q, et al. NF-kappaB and Nrf2 signaling pathways contribute to wogonin-mediated inhibition of inflammation-associated colorectal carcinogenesis. Cell Death Dis. 2014;5:e1283.

28. Wang H, Zhao L, Zhu LT, et al. Wogonin reverses hypoxia resistance of human colon cancer HCT116 cells via downregulation of HIF-1alpha and glycolysis, by inhibiting PI3K/Akt signaling pathway. Mol Carcinog. 2014;53(suppl 1):E107-E118.

29. He L, Lu N, Dai Q, et al. Wogonin induced G1 cell cycle arrest by regulating Wnt/beta-catenin signaling pathway and inactivating CDK8 in human colorectal cancer carcinoma cells. Toxicology. 2013;312:36-47.

30. Wang CZ, Calway TD, Wen XD, et al. Hydrophobic flavonoids from Scutellaria baicalensis induce colorectal cancer cell apoptosis through a mitochondrial-mediated pathway. Int J Oncol. 2013;42(3):1018-1026.

31. Kim SJ, Kim HJ, Kim HR, et al. Antitumor actions of baicalein and wogonin in HT-29 human colorectal cancer cells. Mol Med Rep. 2012; 6(6):1443-1449

32. Dong $\mathrm{P}$, Zhang Y, Gu J, et al. Wogonin, an active ingredient of Chinese herb medicine Scutellaria baicalensis, inhibits the mobility and invasion of human gallbladder carcinoma GBC-SD cells by inducing the expression of maspin. J Ethnopharmacol. 2011;137(3):1373-1380.

33. Takahashi H, Chen MC, Pham H, et al. Baicalein, a component of Scutellaria baicalensis, induces apoptosis by Mcl-1 down-regulation in human pancreatic cancer cells. Biochim Biophys Acta. 2011;1813(8):1465-1474.

34. Lu QY, Zhang L, Moro A, et al. Detection of baicalin metabolites baicalein and oroxylin-a in mouse pancreas and pancreatic xenografts. Pancreas. 2012;41(4):571-576.

35. Wang CZ, Li XL, Wang QF, Mehendale SR, Yuan CS. Selective fraction of Scutellaria baicalensis and its chemopreventive effects on MCF-7 human breast cancer cells. Phytomedicine. 2010;17(1):63-68.
36. Zhao L, Miao HC, Li WJ, et al. LW-213 induces G2/M cell cycle arrest through AKT/GSK3beta/beta-catenin signaling pathway in human breast cancer cells. Mol Carcinog. 2016;55(5):778-792.

37. Safdari Y, Khalili M, Ebrahimzadeh MA, Yazdani Y, Farajnia S. Natural inhibitors of PI3K/AKT signaling in breast cancer: emphasis on newlydiscovered molecular mechanisms of action. Pharmacol Res. 2015;93: $1-10$.

38. Huang KF, Zhang GD, Huang YQ, et al. Wogonin induces apoptosis and down-regulates survivin in human breast cancer MCF-7 cells by modulating PI3K-AKT pathway. Int Immunopharmacol. 2012;2(2): 334-341.

39. Yu JS, Kim AK. Wogonin induces apoptosis by activation of ERK and p38 MAPKs signaling pathways and generation of reactive oxygen species in human breast cancer cells. Mol Cells. 2011;31(4):327-335.

40. Chen P, Lu N, Ling Y, et al. Inhibitory effects of wogonin on the invasion of human breast carcinoma cells by downregulating the expression and activity of matrix metalloproteinase-9. Toxicology. 2011;282(3): 122-128.

41. Li HY, Hu J, Zhao S, et al. Comparative study of the effect of baicalin and its natural analogs on neurons with oxygen and glucose deprivation involving innate immune reaction of TLR2/TNFalpha. J Biomed Biotechnol. 2012;2012:267890.

42. Lim JS, Yoo M, Kwon HJ, Kim H, Kwon YK. Wogonin induces differentiation and neurite outgrowth of neural precursor cells. Biochem Biophys Res Commun. 2010;402(1):42-47.

43. Chen S, Corteling R, Stevanato L, Sinden J. Natural inhibitors of indoleamine 3,5-dioxygenase induced by interferon-gamma in human neural stem cells. Biochem Biophys Res Commun. 2012;429(1-2): 117-123.

44. Yeh CH, Shih HC, Hong HM, et al. Protective effect of wogonin on proinflammatory cytokine generation via Jak1/3-STAT1/3 pathway in lipopolysaccharide stimulated BV2 microglial cells. Toxicol Ind Health. 2015;31(10):960-966.

45. Chen S, Xiong J, Zhan Y, Liu W, Wang X. Wogonin inhibits LPSinduced inflammatory responses in rat dorsal root ganglion neurons via inhibiting TLR4-MyD88-TAK1-mediated NF-kappaB and MAPK signaling pathway. Cell Mol Neurobiol. 2015;35(4):523-531.

46. Ha SK, Moon E, Ju MS, et al. 6-Shogaol, a ginger product, modulates neuroinflammation: a new approach to neuroprotection. Neuropharmacology. 2012;63(2):211-223.

47. Parajuli P, Joshee N, Chinni SR, et al. Delayed growth of glioma by Scutellaria flavonoids involve inhibition of Akt, GSK-3 and NF-kappaB signaling. J Neurooncol. 2011;101(1):15-24.

48. Wang Y, Zhang Y, Qian C, et al. GSK3beta/beta-catenin signaling is correlated with the differentiation of glioma cells induced by wogonin. Toxicol Lett. 2013;222(2):212-223.

49. Lin CW, Shen SC, Chien CC, Yang LY, Shia LT, Chen YC. 12-Otetradecanoylphorbol-13-acetate-induced invasion/migration of glioblastoma cells through activating PKCalpha/ERK/NF-kappaBdependent MMP-9 expression. J Cell Physiol. 2010;225(2):472-481.

50. Tsai CF, Yeh WL, Huang SM, Tan TW, Lu DY. Wogonin induces reactive oxygen species production and cell apoptosis in human glioma cancer cells. Int J Mol Sci. 2012;13(8):9877-9892.

51. Ge W, Yin Q, Xian H. Wogonin induced mitochondrial dysfunction and endoplasmic reticulum stress in human malignant neuroblastoma cells via IRE1alpha-dependent pathway. J Mol Neurosci. 2015; 56(3):652-662.

52. Lee DH, Lee TH, Jung CH, Kim YH. Wogonin induces apoptosis by activating the AMPK and p53 signaling pathways in human glioblastoma cells. Cell Signal. 2012;24(11):2216-2225.

53. Xu S, Zhao X, Zhao Q, et al. Wogonin prevents rat dorsal root ganglion neurons death via inhibiting tunicamycin-induced ER stress in vitro. Cell Mol Neurobiol. 2015;35(3):389-398.

54. Gao J, Zhao H, Hylands PJ, Corcoran O. Secondary metabolite mapping identifies Scutellaria inhibitors of human lung cancer cells. J Pharm Biomed Anal. 2010;53(3):723-728. 
55. Gao J, Morgan WA, Sanchez-Medina A, Corcoran O. The ethanol extract of Scutellaria baicalensis and the active compounds induce cell cycle arrest and apoptosis including upregulation of p53 and Bax in human lung cancer cells. Toxicol Appl Pharmacol. 2011;254(3):221-228.

56. Yang L, Wang Q, Li D, et al. Wogonin enhances antitumor activity of tumor necrosis factor-related apoptosis-inducing ligand in vivo through ROS-mediated downregulation of cFLIPL and IAP proteins. Apoptosis. 2013;18(5):618-626.

57. Zhao Y, Yao J, Wu XP, et al. Wogonin suppresses human alveolar adenocarcinoma cell A549 migration in inflammatory microenvironment by modulating the IL-6/STAT3 signaling pathway. Mol Carcinog. 2015;54(suppl 1):E81-E93.

58. Gong WY, Wu JF, Liu BJ, et al. Flavonoid components in Scutellaria baicalensis inhibit nicotine-induced proliferation, metastasis and lung cancer-associated inflammation in vitro. Int J Oncol. 2014; 44(5):1561-1570.

59. Yang L, Zhang HW, Hu R, et al. Wogonin induces G1 phase arrest through inhibiting Cdk4 and cyclin D1 concomitant with an elevation in p21Cip1 in human cervical carcinoma HeLa cells. Biochem Cell Biol. 2009;87(6):933-942.

60. Kim MS, Bak Y, Park YS, et al. Wogonin induces apoptosis by suppressing E6 and E7 expressions and activating intrinsic signaling pathways in HPV-16 cervical cancer cells. Cell Biol Toxicol. 2013; 29(4):259-272.

61. Chow SE, Chang YL, Chuang SF, Wang JS. Wogonin induced apoptosis in human nasopharyngeal carcinoma cells by targeting GSK-3beta and DeltaNp63. Cancer Chemother Pharmacol. 2011;68(4):835-845.

62. Chow SE, Chen YW, Liang CA, Huang YK, Wang JS. Wogonin induces cross-regulation between autophagy and apoptosis via a variety of Akt pathway in human nasopharyngeal carcinoma cells. J Cell Biochem. 2012;113(11):3476-3485.

63. Lin CC, Kuo CL, Lee MH, et al. Wogonin triggers apoptosis in human osteosarcoma U-2 OS cells through the endoplasmic reticulum stress, mitochondrial dysfunction and caspase-3-dependent signaling pathways. Int J Oncol. 2011;39(1):217-224.

64. Zhao K, Wei L, Hui H, et al. Wogonin suppresses melanoma cell B16F10 invasion and migration by inhibiting Ras-medicated pathways. PLoS One. 2014;9(9):e106458.

65. Polier G, Giaisi M, Kohler R, et al. Targeting CDK9 by wogonin and related natural flavones potentiates the anti-cancer efficacy of the Bcl-2 family inhibitor ABT-263. Int J Cancer. 2015;136(3):688-698.

66. Witzens-Harig M, Giaisi M, Kohler R, Krammer PH, Li-Weber M. HTLV1-associated adult T cell leukemia is highly susceptible to Navitoclax due to enhanced Bax expression. Int J Cancer. 2016;138(2):507-514.

67. Zhao Q, Wang J, Zou MJ, et al. Wogonin potentiates the antitumor effects of low dose 5-fluorouracil against gastric cancer through induction of apoptosis by down-regulation of NF-kappaB and regulation of its metabolism. Toxicol Lett. 2010;197(3):201-210.
68. Zhao L, Sha YY, Zhao Q, et al. Enhanced 5-fluorouracil cytotoxicity in high COX-2 expressing hepatocellular carcinoma cells by wogonin via the PI3K/Akt pathway. Biochem Cell Biol. 2013;91(4):221-229.

69. Enomoto R, Koshiba C, Suzuki C, Lee E. Wogonin potentiates the antitumor action of etoposide and ameliorates its adverse effects. Cancer Chemother Pharmacol. 2011;67(5):1063-1072.

70. Attia SM, Ahmad SF, Harisa GI, Mansour AM, El Sayed el SM, Bakheet SA. Wogonin attenuates etoposide-induced oxidative DNA damage and apoptosis via suppression of oxidative DNA stress and modulation of OGG1 expression. Food Chem Toxicol. 2013;59:724-730.

71. Wang T, Gao J, Yu J, Shen L. Synergistic inhibitory effect of wogonin and low-dose paclitaxel on gastric cancer cells and tumor xenografts. Chin J Cancer Res. 2013;25(5):505-513.

72. Tian J, Wang L, Wang L, Ke X. A wogonin-loaded glycyrrhetinic acid-modified liposome for hepatic targeting with anti-tumor effects Drug Deliv. 2014;21(7):553-559.

73. Qian C, Wang Y, Zhong Y, et al. Wogonin-enhanced reactive oxygen species-induced apoptosis and potentiated cytotoxic effects of chemotherapeutic agents by suppression Nrf2-mediated signaling in HepG2 cells. Free Radic Res. 2014;48(5):607-621.

74. Yang H, Hui H, Wang Q, et al. Wogonin induces cell cycle arrest and erythroid differentiation in imatinib-resistant K562 cells and primary CML cells. Oncotarget. 2014;5(18):8188-8201.

75. Xu X, Zhang Y, Li W, et al. Wogonin reverses multi-drug resistance of human myelogenous leukemia K562/A02 cells via downregulation of MRP1 expression by inhibiting Nrf2/ARE signaling pathway. Biochem Pharmacol. 2014;92(2):220-234.

76. Zhong Y, Zhang F, Sun Z, et al. Drug resistance associates with activation of Nrf2 in MCF-7/DOX cells, and wogonin reverses it by downregulating Nrf2-mediated cellular defense response. Mol Carcinog. 2013;52(10):824-834.

77. Ishii K, Tanaka S, Kagami K, et al. Effects of naturally occurring polymethyoxyflavonoids on cell growth, p-glycoprotein function, cell cycle, and apoptosis of daunorubicin-resistant T lymphoblastoid leukemia cells. Cancer Invest. 2010;28(3):220-229.

78. Lee E, Enomoto R, Koshiba C, Hirano H. Inhibition of P-glycoprotein by wogonin is involved with the potentiation of etoposide-induced apoptosis in cancer cells. Ann N Y Acad Sci. 2009;1171:132-136.

79. Chen S, Cooper M, Jones M, et al. Combined activity of oridonin and wogonin in advanced-stage ovarian cancer cells: sensitivity of ovarian cancer cells to phyto-active chemicals. Cell Biol Toxicol. 2011; 27(2):133-147.

80. He F, Wang Q, Zheng XL, et al. Wogonin potentiates cisplatin-induced cancer cell apoptosis through accumulation of intracellular reactive oxygen species. Oncol Rep. 2012;28(2):601-605.
OncoTargets and Therapy

\section{Publish your work in this journal}

OncoTargets and Therapy is an international, peer-reviewed, open access journal focusing on the pathological basis of all cancers, potential targets for therapy and treatment protocols employed to improve the management of cancer patients. The journal also focuses on the impact of management programs and new therapeutic agents and protocols on

\section{Dovepress}

patient perspectives such as quality of life, adherence and satisfaction. The manuscript management system is completely online and includes a very quick and fair peer-review system, which is all easy to use. Visit http://www.dovepress.com/testimonials.php to read real quotes from published authors. 